\title{
EVALUASI PROGRAM PENCEGAHAN KECELAKAAN KENDARAAN DI PT FREEPORT INDONESIA
}

\author{
EVALUATION OF VEHICLE ACCIDENT PREVENTION PROGRAM AT PT FREEPORT INDONESIA
}

\author{
Oong Supratikno*)1, Rizal Syarief*), Dikky Indrawan*) \\ ${ }^{*}$ Sekolah Bisnis, IPB University \\ Jl. Pajajaran Bogor 16151, Indonesia
}

\begin{abstract}
PT Freeport Indonesia (PT FI) applies strict rule to prevent vehicle accident. In fact, the number of vehicle accident is recorded highly enough. The objectives of the research are to (1) identify the most influential factor to the number of light vehicle accident; (2) formulate the right planning to reduce the number of light vehicle accident; (3) provide recommendation to PT FI management to reduce the number of light vehicle accident at PT FI. The research applies used primary and secondary data resource. Secondary data taken from report data of vehicle accident is grouped using Contributory Factor Interaction Model (CFIM) to identify the causing factor of the accidents cause. Afterwards, identification of program improvement planning is conducted using Analytical Hierarchy Process (AHP). The result of the research conveys that the most influential factor of light vehicle accident at PT FI is unsafe behavior of the driver. The right planning to reduce the number of light vehicle accident at PT FI, it is suggested to is conduct the human resources planning by providing training to improve soft skill and hard skill of the driver. Based on this influential factor and the AHP result, the right planning as a recommendation to PT FI Management to reduce the number of light vehicle accident is by applying short-and long-term human resources planning.
\end{abstract}

Keywords: vehicle accident, AHP, CFIM, prevention, light vehicle operation

Abstrak: PT Freeport Indonesia (PT FI) menerapkan aturan yang ketat untuk mencegah kecelakaan kendaraan. Pada kenyataannya angka kecelakaan akibat pengoperasian kendaraan ringan tercatat masih cukup tinggi. Penelitian ini bertujuan (1) mengidentifikasi faktor yang paling berpengaruh terhadap jumlah kecelakaan akibat pengoperasian kendaraan ringan di PT FI; (2) merumuskan perencanaan yang tepat untuk menurunkan jumlah kecelakaan akibat pengoperasian kendaraan ringan di PT FI; (3) memberikan rekomendasi yang akan dilakukan oleh manajemen PT FI untuk menurunkan jumlah kecelakaan akibat pengoperasian kendaraan ringan di PT FI. Penelitian ini menggunakan jenis sumber data primer dan sekunder. Data sekunder dari data laporan kencelakaan kendaraan dikelompokkan menggunakan Contributory Factor Interaction Model (CFIM) untuk mengidentifikasi faktor penyebab keceakaan. Selanjutnya dilakukan identifikasi perencanaan perbaikan program menggunakan Analytical Hierarchy Process (AHP). Hasil penelitian menyatakan bahwa faktor yang paling berpengaruh terhadap kecelakaan akibat pengoperasian kendaraan ringan di PT FI adalah akibat perilaku tidak aman pengemudi. Perencanaan yang paling tepat untuk menurunkan jumlah kecelakaan akibat pengoperasian kendaraan ringan di PT FI adalah perencanaan sumberdaya manusia dengan memberikan pelatihan peningkatan softskill dan hardskill pada pengemudi. Berdasarkan faktor yang memengaruhi dan hasil AHP, perencanaan yang paling tepat sebagai rekomendasi menurunkan kecelakaan akibat pengoperasian kendaraan kepada manajemen PT FI adalah dengan menerapkan perencanaan sumber daya manusia jangka pendek dan jangka panjang.

Kata kunci: kecelakaan kendaraan, AHP, CFIM, pencegahan, pengoperasian kendaraan

\footnotetext{
${ }^{1}$ Alamat korespondensi:

Email: osuprati@fmi.com
} 


\section{PENDAHULUAN}

PT Freeport Indonesia (PT FI) menggunakan kendaraan ringan sebagai salah satu sarana transportasi karyawan melakukan aktifitasnya untuk menunjang kegiatan pertambangan. Kategori kendaraan ringan/Light Vehicle $(L V)$ di PT FI adalah kendaraan untuk mengangkut orang dengan maksimum 16 kapasitas tempat duduk dan berat kendaraan kurang dari empat ton. PT FI menerapkan aturan lisensi yang wajib dimiliki oleh pengemudi untuk dapat mengoperasikan kendaraan ringan. Lisensi kendaraan ringan terbagi menjadi lima area sesuai tingkat kesulitannya, yaitu area dataran rendah (lowland), area dataran tinggi (highland), area tambang terbuka (surface mine), area tambang bawah tanah (underground) dan area HEAT Road. PT FI juga mempunyai peraturan berlalu lintas yang ketat yang dituangkan pada PT FI Traffic Rules.

Data kecelakaan menunjukkan di area kerja PT FI setiap tahunnya tercatat kejadian kecelakaan kendaraan ringan dengan jumlah yang tinggi. Kecelakaan dengan kategori ringan hingga berat. Data dari divisi Occupational Health and Safety (OHS) PT FI pada tahun 2017 tercatat sejumlah 276 kecelakaan, tahun 2018 terjadi sebanyak 365 kecelakaan dan di tahun 2019 terjadi sejumlah 353 kecelakaan. PT FI selalu melakukan perbaikan terhadap program pencegahan kecelakaan akibat pengoperasian kendaraan. Bulan Juni 2020 PT FI kembali melakukan perubahan untuk perbaikan program pencegahan kecelakaan kendaraan. Perubahan ini melibatkan tiga divisi, yaitu divisi Learning and Organizational (L\&OD), divisi OHS, dan divisi Maintenance. Divisi $L \& O D$ melakukan perubahan pada prosedur untuk mendapatkan lisensi kendaraan ringan dengan memberikan penambahan peraturan baru, sebelum melakukan tes tertulis dan tes praktek calon pengemudi harus mendapatkan serangkaian pelatihan pembekalan berupa pelatihan $L V$ Awareness secara teori di dalam kelas dan praktik penanganan kondisi darurat menggunakan LV Simulator. Divisi OHS melakukan evaluasi terhadap peraturan, prosedur dan rambu-rambu jalan serta melakukan razia / sweeping terhadap pengemudi untuk memastikan kepatuhan terhadap aturan. Divisi Maintenance membuat jadwal Prefentive Maintenance (PM) khusus pemeriksaan brake system setiap kendaraan menempuh jarak 2500 KM. Setelah dijalankan program ini kecelakaan kendaraan ringan bulan Juli hingga November 2020 rata-rata sebanyak 15 kali kejadian per bulan. Lebih rendah jika dibandingkan rata-rata kecelakaan bulan
Januari hingga Juni 2020 yaitu rata-rata 25 kali kejadian per bulan dan di tahun 2019 rata-rata sebanyak 29 kali kecelakaan per bulan. Meskipun dari data laporan kecelakaan diatas menunjukkan setelah diterapkan program perbaikan pencegahan kecelakaan berdampak positif, namun tidak boleh hanya berhenti disini.

Rata-rata kecelakaan 15 kali kejadian perbulan harus diturunkan lagi dan jika perlu dihilangkan. Banyaknya kecelakaan yang menyebabkan kerusakan tentunya berakibat pada tingginya biaya yang dikeluarkan oleh perusahaan. Selain itu dapat mengganggu produktifitas dan merusak citra perusahaan yang tidak bisa menjaga keselamatan karyawannya sebagai aset yang paling berharga. Diperlukan evaluasi lebih lanjut terhadap program pencegahan kecelakaan kendaraan ringan yang saat ini sedang berjalan. Kecelakaan bisa diakibatkan kurangnya kewaspadaan dan kondisi jalan (Herawati, 2014). Rendahnya pemahaman terhadap peraturan dalam berkendara juga menyebabkan tingginya jumlah kecelakaan (Kordelia et al. 2014). Sebagai upaya untuk menurunkan jumlah kecelakaan, maka diperlukan penelitian untuk mengetahui faktor apa yang paling berpengaruh terhadap jumlah kecelakaan akibat pengoperasian kendaraan ringan di area kerja PT FI yang saat ini masih terjadi. Perencanaan yang perlu dirumuskan untuk menurunkan jumlah kecelakaan akibat pengoperasian kendaraan ringan dan program yang harus dilakukan oleh manajemen PT FI untuk menurunkan jumlah kecelakaan akibat pengoperasian kendaraan ringan.

Penelitian terdahulu yang relevan adalah penelitian yang dilakukan oleh Zhang et al. (2018). Penelitian dilakukan pada kecelakaan kendaraan yang terjadi dijalan raya. Faktor yang paling berpengaruh menjadi penyebab kecelakaan kendaraan didapatkan dari pengelompokan-pengelompokan penyebab kecelakaan yang sudah terjadi. Penelitian lain dilakukan oleh Qin dan Zhang (2016), penelitian dilakukan pada jalan tambang yang terletak di daerah pegunungan, banyak tebing, tikungan tajam dan jalan yang curam sama halnya dengan kondisi jalan tambang di PT FI. Evaluasi keselamatan kendaraan menggunakan Fuzzy AHP. Hasil penelitian menunjukkan bahwa indeks lingkungan luar bernilai 0,101 , fasilitas keselamatan bernilai 0,236 dan teknologi keamanan bernilai 0,663.

Kebaruan dari penelitian ini adalah menggabungkan penelitian untuk mendapatkan faktor yang berpengaruh terhadap kecelakaan kendaraan sekaligus 
melakukan identifikasi untuk mendapatkan perbaikan program pencegahan terhadap kecelakan akibat pengoperasian kendaraan. Pendekatan penyelesaian masalah menggunakan data sekunder kecelakaan kendaraan yang tercataat di PT FI. Faktor-faktor yang berpengaruh terhadap kecelakaan kendaraan didapatkan dari pengelompokan penyebab kecelakaan hasil investigasi. Indentifikasi perbaikan program pencegahan kecelakaan melalui diskusi dan pendapat pakar selanjutnya dianalisis menggunakan Analytical Hierarchy Process (AHP).

Tujuan dari penelitian ini adalah (1) mengidentifikasi faktor yang paling berpengaruh terhadap jumlah kecelakaan akibat pengoperasian kendaraan ringan di PT FI; (2) merumuskan perencanaan yang tepat untuk menurunkan jumlah kecelakaan akibat pengoperasian kendaraan ringan di PTFI; (3) memberikan rekomendasi yang akan dilakukan oleh manajemen PT FI untuk menurunkan jumlah kecelakaan akibat pengoperasian kendaraan ringan di PT FI. Ruang lingkup penelitian ini menitikberatkan pada perencanaan menurunkan jumlah kerusakan properti dan cidera akibat kecelakaan pengoperasian kendaraan ringan di area kerja PT Freeport Indonesia.

\section{METODE PENELITIAN}

Penelitian ini merupakan studi kasus di area kerja PT FI yang berlokasi di kabupaten Mimika, propinsi Papua. Pertimbangannya adalah ketersediaan data dan kesediaan dari perusahaan untuk dilakukan penelitian tentang keselamatan pengoperasian kendaraan ringan. Waktu penelitian dilakukan bulan Juli 2020 sampai dengan bulan bulan Desember 2020.

Penelitian ini menggunakan jenis dan sumber data sekunder dan data primer. Data sekunder yang digunakan adalah data laporan kecelakaan kendaraan ringan yang digunakan untuk mengidentifikasi faktor yang menyebabkan kecelakaan kendaraan ringan. Data primer didapat dari narasumber yang selanjutnya disebut pakar. Wawancara dan survei digunakan sebagai teknik pengambilan data primer. Wawancara terhadap narasumber ahli merupakan suatu pendekatan kualitatif berdasarkan topik yang ditentukan untuk mendapatkan informasi-informasi yang dibutuhkan berdasarkan bidang keahliannya (Meuser dan Nagel, 2009). Informasi dari pakar diperlukan untuk mendapatkan penilaian dari variable-variabel penelitian. Narasumber pada penelitian ini sebanyak lima orang. Satu orang assessor lisensi mengemudi kendaraan ringan PT FI, satu orang petugas $O H S$ PT FI, dua orang petugas $O H S$ Non-PT FI dan satu orang responden external yang merupakan praktisi keselamatan jalan - Politeknik APP dan instructor dari Indonesian Defensive Driving Center (IDDC) Instructor. Metode yang digunakan untuk melakukan identifikasi faktor-faktor penyebab kecelakaan adalah Contributory Factor Interaction Model (CFIM). Data sekunder penyebab kecelakaan berdasarkan hasil investigasi dikelompok-kelompokkan menggunakan CFIM untuk mendapatkan faktor-faktor penyebab kecelakaan.

Metode untuk identifikasi perbaikan program menggunakan Analytical Hierarchy Process (AHP). Langkah-langkah metode AHP adalah menyusun hirarki AHP, membuat kuesioner untuk diberikan penilaian oleh pakar dan mengolah data dari kuesioner menggunakan software super decission 2.8.0. Hipotesis pada penelitian ini berdasarkan pada penelitian sebelumnya yang dilakukan oleh Qin dan Zhang (2016). Pada penelitian tersebut teknologi keamanan, fasilitas keselamatan dan lingkungan luar adalah faktor yang berpengaruh dalam kecelakaan akibat pengoperasian kendaraan di jalan tambang.

Kerangka pemikiran penelitian ini ditunjukkan pada Gambar 1. PT FI memiliki permasalahan dengan jumlah kecelakaan yang tinggi akibat pengoperasian kendaraan ringan. Evaluasi dilakukan pada program pencegahan kecelakaan yang sudah berjalan saat ini berdasarkan data-data yang ada. Faktor-faktor penyebab kecelakaan akibat pengoperasian kendaraan harus diketahui untuk mendapatkan perbaikan program pencegahan kecelakaan yang tepat. Identifikasi faktor yang menyebabkan kecelakaan kendaraan memerlukan data sekunder. Data sekunder yang digunakan adalah informasi kecelakaan kendaraan yang tercatat pada divisi OHS - PT FI tanggal 1 Juli 2020 sampai dengan 30 November 2020. Data kecelakaan kendaraan ringan yang digunakan sebagai dasar menentukan faktor penyebab kecelakaan adalah data pada pada Daily Incident Report, Internal Safety Incident Investigation Report (ISIIR) dan Incident Management System (IMS). Melalui metode CFIM, data sekunder dikelompokkan untuk menentukan faktor-faktor penyebab kecelakaan, (Zhang et al. 2018). Ulasan literatur juga digunakan untuk mendapatkan informasi mengenai faktor-faktor yang memengaruhi kecelakaan akibat pengoperasian kendaraan. Informasi-informasi yang didapatkan 
selanjutnya didiskusikan dengan narasumber/pakar untuk mengetahui faktor apa saja yang relevan dengan penelitian melalui wawancara (Bogner dan Menz, 2009). Faktor-faktor penyebab kecelakaan yang sudah teridentifikasi selanjutnya digunakan untuk menyusun hirarki AHP (Gambar 2). AHP dipilih sebagai metode analisis untuk identifikasi perbaikan program upaya pencegahan kecelakaan pada penelitian ini. Kelebihan metode AHP diantaranya unity, complexity, inter dependence, hierarchy structuring, measurement, consistency, synthesis, trade off (Saaty, 1986; Saaty, 1987). Kuesioner digunakan untuk mendapatkan penilaian dari pakar. Analisis dilakukan terhadap data dari kuesioner dan mendapatkan alternatif yang relevan untuk perbaikan perencanaan pencegahan kecelakaan kendaraan. Alternatif dengan bobot tertinggi menjadi pilihan sebagai implikasi manajerial sebagai upaya untuk perbaikan program pencegahan kecelakaan akibat pengoperasian kendaraan ringan.

\section{HASIL}

\section{Gambaran Kondisi Jalan di PT Freeport Indonesia}

Area kerja PT FI cukup luas, mulai dari pelabuhan Amamapare (Portsite) di dataran rendah hingga dataran tinggi Grasberg dengan ketinggian lebih dari 4200 meter diatas permukaan laut (mdpl). Kondisi dan karakter jalan di dataran rendah berbeda dengan di dataran tinggi. Tingkat kesulitan dan bahaya yang ditimbulkan juga berbeda-beda. PT FI menerapkan lisensi mengemudi berdasarkan tingkat kesulitan masing-masing area. Lisensi mengemudi dibagi menjadi lima area sertifikasi. Lisensi area Lowland untuk area Portsite sampai Mile Post (MP) 50. Kondisi jalan lurus, lebar dan berdebu. Pada ketinggian 0 - 525 mdpl. Berbagai jenis kendaraan ringan yang dioperasikan dan tidak memerlukan spesifikasi khusus seperti Four Wheel Drive (4WD). Lisensi area Highland untuk area $M P 50$ sampai MP 74. Kondisi jalan terjal, sempit, berbelok-belok, berkabut, curah hujan tinggi dan licin. Pada ketinggian 525-3400 mdpl. Jenis kendaraan ringan yang dioperasikan adalah Toyota Hilux, Toyota Land Cruiser, Ford Ranger dan Ford Everest. Memerlukan spesifikasi khusus 4WD. Lisensi area Surface Mine untuk area tambang terbuka Grasberg. Kondisi jalan terjal, berbelok-belok, berkabut, curah hujan tinggi dan licin. Pada ketinggian 3700-4200 mdpl. Jenis kendaraan ringan yang dioperasikan hanya Toyota Land Cruiser. Lisensi area Underground untuk area tambang bawah tanah. Kondisi jalan gelap, sempit, berbelokbelok, berlumpur, bahaya batuan jatuh dan bahaya alat berat yang beroperasi. Pada ketinggian 2500 - 3000 mdpl. Jenis kendaraan ringan yang dioperasikan adalah Toyota Hilux, Toyota Land Cruiser, Ford Ranger dan Ford Everest. Lisensi area HEAT Road, dengan kondisi jalan terjal, berbelok-belok, berkabut, curah hujan tinggi, licin dan rawan longsor. Pada ketinggian 2500 $3800 \mathrm{mdpl}$. Jenis kendaraan ringan yang dioperasikan hanya Toyota Land Cruiser.

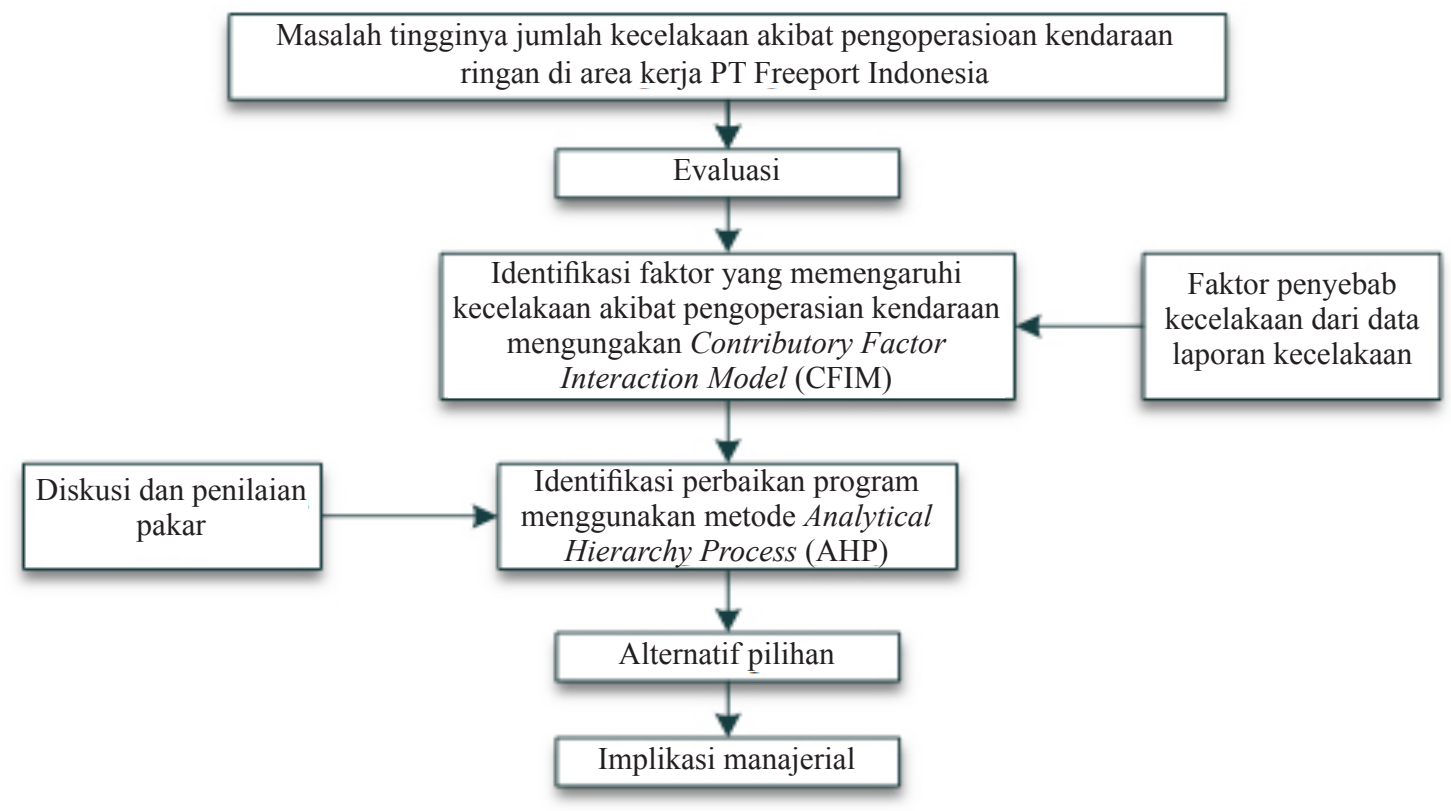

Gambar 1. Kerangka pemikiran penelitian 


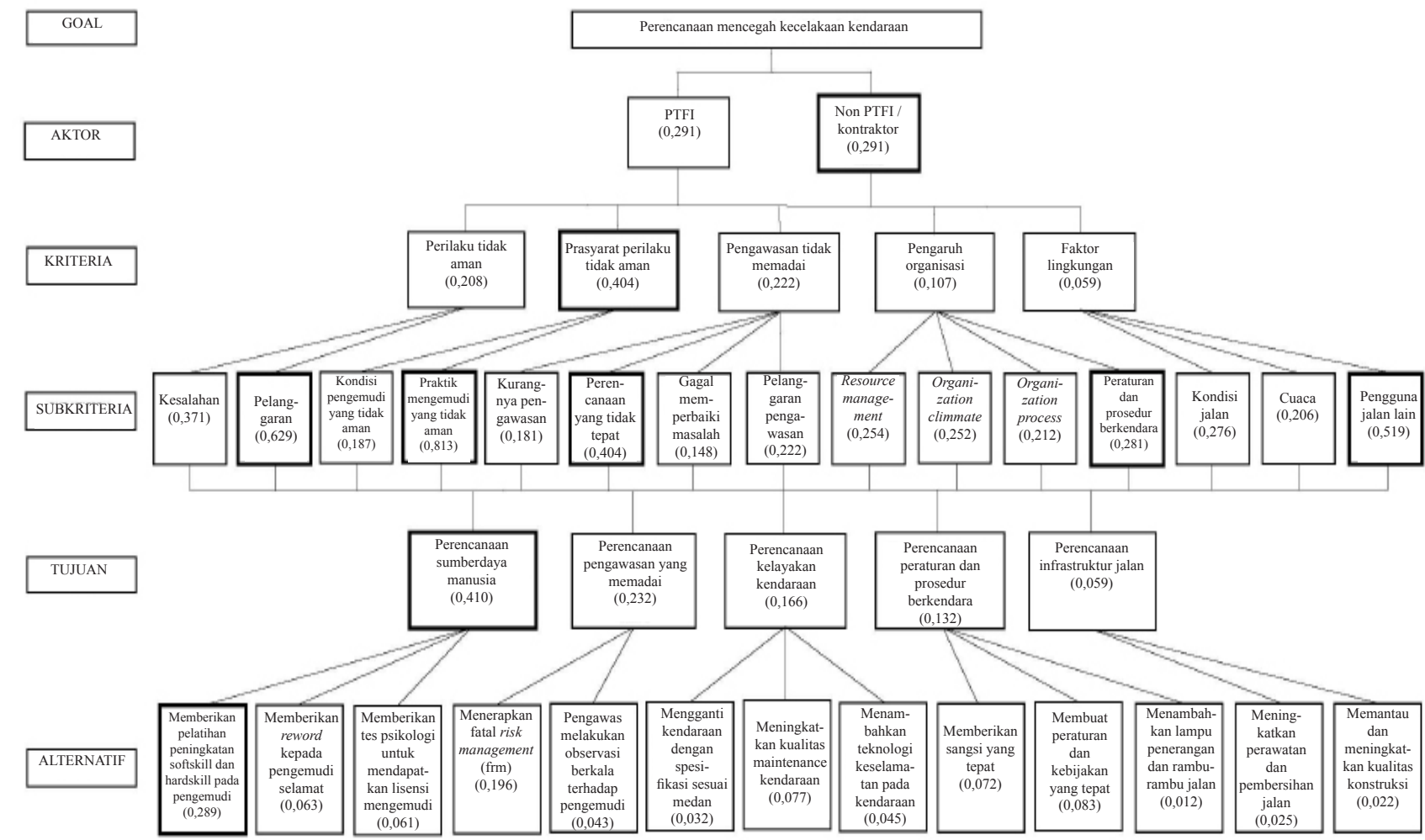

Gambar 2. Hierarki AHP

\section{Identifikasi Faktor Penyebab Kecelakaan}

Data kecelakaan kendaraan yang tercatat di PT FI cukup terbatas sehingga tidak bisa mendapatkan data secara keseluruhan. Data kecelakaan kendaraan ringan yang digunakan sebagai dasar menentukan faktor penyebab kecelakaan adalah data pada pada Daily Incident Report, Internal Safety Incident Investigation Report (ISIIR) dan Incident Management System (IMS). Data causal factor kecelakaan kendaraan ringan secara lengkap yang bisa didapatkan hanya antara bulan Juli 2020 sampai dengan bulan November 2020. Data penyebab kecelakaan hasil investigasi yang tercatat pada ISIIR dan IMS pada periode bulan ini dikelompokkan menggunakan Contributory Factor Interaction Model (CFIM), (Zhang et al. 2018) untuk menentukan faktorfaktor penyebab kecelakaan. Pada CFIM terbagi menjadi lima ketegori penyebab kecelakaan, yaitu perilaku tidak aman, prasyarat perilaku tidak aman, pengawasan tidak memadai, pengaruh organisasi dan faktor lingkungan. Kategori perilaku tidak aman dibagi menjadi dua subkategori, yaitu kesalahan dan pelanggaran. Kategori prasyarat perilaku tidak aman juga dibagi menjadi dua subkategori, yaitu kondisi pengemudi yang tidak aman dan praktik mengemudi dibawah standar. Kategori pengawasan tidak memadai dibagi menjadi empat subkategori, yaitu kurangnya pengawasan, perencanaan yang tidak tepat, gagal memperbaiki masalah dan pelanggaran pengawasan. Kategori pengaruh organisasi dibagi menjadi empat subkategori, yaitu resource management, organization climmate, organization process dan peraturan dan prosedur berkendara. Kategori faktor lingkungan dibagi menjadi tiga subkategori, yaitu kondisi jalan, cuaca dan pengguna jalan lain. Akar penyebab kecelakaan hasil investigasi pada ISIIR dan IMS dimasukkan pada masing-masing subkriteria sesuai pengelompokannya. Hasil pengelompokan ini mendapatkan tiga kelompok kategori/faktor yang berpengaruh terhadap jumlah kecelakaan akibat pengoperasian kendaraan ringan di PT FI. Kelompok kategori yang pertama adalah perilaku tidak aman (82,7\%), dengan subkategori kesalahan sebesar $62,2 \%$ dan pelanggaran $20,5 \%$. Kedua, pengawasan tidak memadai $(6,4 \%)$, dengan subkategori gagal memperbaiki masalah sebesar 6,4\%. Dan ke tiga, pengaruh organisasi $(10,9 \%)$, dengan subkategori resource management sebesar 10,9\%. Data yang ditampilkan diatas hanya dalam kurun waktu lima bulan, faktor lain di luar bulan ini diasumsikan serupa. 


\section{Identifikasi Perbaikan Program}

Pada penelitian ini AHP digunakan sebagai metode untuk menentukan perencanaan dalam perbaikan program pencegahan kecelakaan akibat pengoperasian kendaraan ringan di PT FI. Pada metode AHP ada tiga prisip yang harus dilakukan, yaitu dekomposisi, penilaian perbandingan dan sintesis prioritas (Saaty, 1986). Hierarki disusun dari tingkat atas yang merupakan fokus dari sudut pandang manajerial, kemudian tingkat menengah yang berupa kriteria di mana tingkat selanjutnya bergantung ke tingkat terendah yang biasanya berupa daftar alternatif (Kearns dan Saaty, 1985).

Hirarki AHP pada penelitian ini disusun menjadi enam level (Gambar 2). Level pertama adalah goal yaitu perencanaan mencegah kecelakaan kendaraan. Level ke dua yaitu aktor. Pengemudi kendaraan ringan di PT FI bukan hanya karyawan PT FI saja, namun juga karyawan mitra atau perusahaan kontraktor/Non-PT FI yang mendukung operasional PT FI. Oleh karena itu pada level aktor ini menggunakan dua elemen, yaitu PT FI dan Non-PT FI/Kontraktor. Level ketiga adalah kriteria. Untuk mendapatkan analisa yang lebih akurat maka lima kategori pada CFIM dimasukkan semua pada level kriteria hirarki AHP. Lima kriteria ini, yaitu perilaku tidak aman, prasyarat perilaku tidak aman, pengawasan tidak memadai, pengaruh organisasi dan faktor lingkungan. Level keempat adalah subkriteria. PadalevelinidimasukkansemuasubkategoripadaCFIM menjadi elemen subkriteria. Maka elemen lima belas subkriteria ini adalah: kesalahan, pelanggaran, kondisi pengemudi yang tidak aman, praktik mengemudi yang tidak aman, kurangnya pengawasan, perencanaan yang tidak tepat, gagal memperbaiki masalah, pelanggaran pengawasan resource management, organization climate, organization process, peraturan dan prosedur berkendara, kondisi jalan, cuaca dan pengguna jalan lain. Elemen subkriteria dihubungkan dengan elemen kriteria berdasarkan pengelompokan pada CFIM. Level kelima adalah tujuan. Pada level ini hasil diskusi dengan pakar berdasarkan elemen kriteria dan subkriteria maka ditentukan lima elemen. Elemen pada level tujuan ini yaitu: perencanaan sumberdaya manusia, perencanaan pengawasan yang memadai, perencanaan kelayakan kendaraan, perencanaan dan peraturan prosedur berkendara dan perencanaan infrastruktur jalan. Level terakhir adalah alternatif. Pada level ini dimasukkan tiga belas elemen yang merupakan hasil kajian literatur dan diskusi dengan pakar, elemen-elemen ini juga merupakan program yang saat ini sudah berjalan maupun yang belum berjalan. Diberikan dua sampai tiga alternatif masing-masing tujuan mendapatkan alternatif yang berpotensi efektif untuk keberhasilan penerapan perencanaan.

1. Memberikan pelatihan peningkatan softskill dan hardskill pada pengemudi: pelatihan peningkatan softskill pada pengemudi bertujuan untuk meningkatkan kepedulian terhadap tanggung jawab dan keselamatan serta meningkatkan pemahaman terhadap peraturan berkendara serta penanganan kondisi daruratseperti rem tidak berfungsi, kerusakan steering dan sebagainya (Zhang dan Kecojevic, 2015). Pelatihan berpengaruh positif dalam upaya meningkatkan motivasi karyawan (Riani et al. 2017) salah satunya dalam hal mematuhi peraturan dan prosedur keselamatan berkendara.

2. Menerapkan Fatal Risk Management (FRM), Pedoman Freeport Safety and Health (FRESH) GDL-504-PT FI-0014 tentang Pengelolaan Risiko Fatal/Fatal Risk Management (FRM). Penerapan manajemen pencegahan keselamatan yang tepat dapat mencegah terjadinya kecelakaan kendaraan (Jeong et al. 2016).

3. Membuat peraturan dan kebijakan yang tepat, mengidentifikasi komponen dan perangkat kebijakan dan melakukan evaluasi serta perbaikan berkesinambungan berdampak positif dalam mengembangkan dan menilai strategi keselamatan jalan raya (Hughes et al. 2016). Peraturan dilarang menggunakan telpon genggam saat berkendara dapat menurunkan jumlah kecelakaan kendaraan (Brusque dan Alauzet, 2008).

4. Meningkatkan kualitas maintenance kendaraan, meningkatkan keamanan kendaraan dan spesifikasi teknis merupakan salah satu strategi pencegahan kecelakaan kendaraan (Sandhyavitri et al. 2017).

5. Memberikan sangsi yang tepat, sangsi yang diterapkan sesuai dengan prosedur yang benar akan berpengaruh besar untuk meningkatkan perilaku pengemudi untuk disiplin mematuhi peraturan berkendara (Holillulloh dan Adha, 2013).

6. Memberikan tes psikologi untuk mendapatkan lisensi mengemudi. Kepribadian pengemudi dapat menjadi faktor penyebab kecelakaan (Trimpop dan Kirkcaldy, 1997).

7. Menambahkan teknologi keselamatan pada kendaraan, penerapan teknologi keselamatan pada kendaraan juga sangat membantu untuk pencegehan kecelakaan kendaraan (Zhang dan Kecojevic, 2015). Perkembangan teknologi dapat membantu 
meningkatkan keselamatan dalam berkendara (Ren et al. 2019)

8. Memberikan reword kepada pengemudi selamat, sekecil apapun pemberian reword akan memberikan pengaruh positif untuk meningkatkan kedisiplinan karyawan terhadap peraturan (Siahaan, 2013).

9. Pengawas/atasan melakukan observasi berkala terhadap pengemudi. Pengawasan yang memadai terhadap pengemudi dapat mengurangi jumlah kecelakaan kendaraan (Xiong dan Mannering, 2013).

10.Mengganti kendaraan sesuai spesifikasi medan, meningkatkan keamanan kendaraan dan spesifikasi teknis merupakan salah satu strategi pencegahan kecelakaan kendaraan (Sandhyavitri et al. 2017).

11. Meningkatkan perawatan dan pembersihan jalan secara berkala, penerapan pemeliharaan jalan yang baik merupakan salah satu strategi dalam pencegahan kecelakaan lalu lintas (Borovik et al. 2018).

12.Memantau dan meningkatkan kualitas konstruksi, menciptakan infrastruktur yang baik dapat meningkatkan keselamatan lalu lintas (Ahmadi et al. 2018).

13. Menambahkan lampu penerangan dan ramburambu jalan, identifikasi daerah rawan kecelakaan, melakukan pemasangan rambu lalu lintas, memperbaiki marka jalan dan pemasangan penerangan jalan untuk meningkatkan strategi keselamatanjalan(Sandhyavitrietal.2017). Ramburambu peringatan harus dipasang pada daerah yang berbahaya. Jalan yang licin bisa menyebabkan kecelakaan (Malin et al. 2019).

Data yang didapatkan melalui kuesioner yang sudah diberikan penilaian oleh pakar dilakukan pengolahan dengan menggunakan software super decision 2.8.0. Consistensy Index (CI) dapat diterima atau disebut konsisten jika $<0,1$. Hasil analisis sebagai berikut:

1. Level aktor, yang berpengaruh terhadap kecelakaan kendaraan di area kerja PT FI adalah pengemudi dari karyawan Non-PT FI / kontraktor, dengan bobot 0,709 , dan $\mathrm{CI}=0$. Hal ini selaras dengan data kecelakaan bulan Juli 2020 sampai dengan November 2020. Pengemudi dari karyawan Non PT FI/kontraktor yang mengalami kecelakaan sebanyak 46 kejadian (62\%), sedangkan pengemudi dari karyawan PT FI sebanyak 28 kejadian (38\%).

2. Level kriteria, yang berpengaruh terhadap kecelakaan kendaraan adalah prasyarat perilaku tidak aman, dengan bobot sebesar 0,404, dan
$\mathrm{CI}=0,03$. Subkriteria yang berpengaruh terhadap kriteria prasyarat perilaku tidak aman adalah praktik mengemudi yang tidak aman (bobot 0,813 ). Praktik mengemudi tidak aman ini bisa disebabkan oleh kurangnya pengetahuan dan keterampilan pengemudi dalam berkendara.

3. Level subkriteria, yang berpengaruh terhadap kecelakaan pada kriteria perilaku tidak aman adalah pelanggaran, dengan bobot 0,629 dan $\mathrm{CI}=0$. Pada kriteria prasyarat perilaku tidak aman adalah praktik mengemudi yang tidak aman dengan bobot 0,813 dan $\mathrm{CI}=0$. Pada kriteria pengawasan yang tidak memadai adalah perencanaan yang tidak tepat, dengan bobot 0,404 dan $\mathrm{CI}=0,08$. Pada kriteria pengaruh organisasi adalah peraturan dan prosedur berkendara, dengan bobot 0,281 dan $\mathrm{CI}=0,03$. Pada faktor lingkungan yang berpengaruh adalah pengguna jalan lain, dengan bobot 0,519 dan $\mathrm{CI}=$ 0,005 .

4. Level tujuan, yang berpengaruh terhadap kecelakaan kendaraan adalah perencanaan sumberdaya manusia, dengan bobot sebesar 0,410 dan $\mathrm{CI}=0,03$. Kriteria yang berperan adalah prasyarat perilaku tidak aman (bobot 0,404). Sedangkan subkriteria yang berpengaruh adalah praktik mengemudi yang tidak aman dengan bobot 0,813 .

5. Level alternatif peringkat tertinggi dengan bobot 0,289 yaitu memberikan pelatihan peningkatan softskill dan hardskill pada pengemudi, dengan CI sebesar 0,03. Alternatif ini merupakan bagian dari tujuan perancanaan sumberdaya manusia (bobot 0,410). Alternatif ini dipengaruhi oleh dua kriteria, yaitu perilaku tidak aman (bobot 0,208) dan prasyarat perilaku tidak aman (bobot 0,404), dipengaruhi juga oleh empat subkriteria, yaitu kesalahan (bobot 0,371), pelanggaran (bobot 0,629 ) kondisi pengemudi yang tidak aman (bobot 0,187 ) dan praktik mengemudi yang tidak aman (bobot 0,813). Berdasarkan data kecelakaan di PT FI antara bulan Juli 2020 sampai dengan November 2020, kriteria perilaku tidak aman menjadi penyebab kecelakaan sebanyak $82,7 \%$, prasyarat perilaku tidak aman sebanyak $0 \%$, sedangkan subkriteria kesalahan sebanyak $62,2 \%$, pelanggaran $20,5 \%$, kondisi pengemudi yang tidak aman $0 \%$ dan praktik mengemudi tidak aman juga $0 \%$. Untuk mencapai goal aktor yang berperan penting dalam alternatif scenario ini adalah karyawan Non PT FI/ Kontraktor. 
Penelitian sebelumnya yang dilakukan oleh Qin dan Zhang (2016) pada evaluasi keselamatan kendaraan jalan tambang menunjukkan bahwa teknologi keamanan yang paling berpengaruh untuk meningkatkan pencegahan kecelakaan kendaraan. Pada penelitian ini menunjukkan bahwa pelatihan peningkatan softskill dan hardskill pada pengemudi yang paling berperan dalam meningkatkan keselamatan dalam berkendara. Penerapan teknologi keselamatan kendaraan pada penelitian ini hanya menempati peringkat tujuh pada level alternatif AHP. Menunjukkan bahwa di PT FI yang paling berperan menjadi penyebab kecelakaan adalah pengemudi yang melakukan kesalahan, pelanggaran, mengemudi dengan kondisi tidak aman dan akibat praktik mengemudi yang tidak aman.

Rekomendasi yang bisa diberikan untuk dilakukan oleh manajemen PT FI untuk menurunkan jumlah kecelakaan kendaraan ringan di PT FI adalah perencanaan sumberdaya manusia (bobot 0,410 ) dengan cara menerapkan alternatif memberikan peningkatan softskill dan hardskill pada pengemudi (bobot 0,289 ). Peningkatan softskill dalam bentuk pelatihan kesadaran berkendara yang aman dan peningkatan pemahaman tentang peraturan berkendara. Pelatihan ini diharapkan mampu menurunkan kecelakaan terkait dengan subkriteria pelanggaran dan kondisi pengemudi yang tidak aman. Pelanggaran yang dilakukan pengemudi seperti gagal mematuhi peraturan dan tidak memastikan kondisi kendaraan yang aman dengan melakukan pemeriksaan awal sebelum operasi diharapkan tidak terjadi lagi. Kondisi pengemudi yang tidak aman yang dapat menyebabkan kecelakaan seperti dalam pengaruh alkohol dan kelelahan dapat dicegah. Peningkatan hardskill dalam bentuk pelatihan peningkatan keterampilan dalam berkendara dilakukan dalam upaya untuk mencegah kecelakaan terkait subkriteria kesalahan dan praktik mengemudi dibawah standar. Kesalahan pengemudi seperti gagal mengamankan dan ketidakmampuan mengambil keputusan yang tepat dapat dicegah. Praktik mengemudi dibawah standar yang menyebabkan kecelakaan seperti kurang pengetahuan dan keterampilan dalam berkendara bisa diantisipasi.

\section{Evaluasi Program Pencegahan Kecelakaan Kendaraan di PT FI}

PT FI menjalankan perubahan program pencegahan kecelakaan kendaraan terbaru mulai bulan Juni 2020. Perubahan ini melibatkan tiga divisi, yaitu divisi
Learning and Organizational (L\&OD), divisi OHS, dan divisi Maintenance. Divisi $L \& O D$ melakukan perubahan pada prosedur untuk mendapatkan lisensi kendaraan ringan dengan memberikan penambahan prosedur pada proses untuk mendapatkan lisensi baru, sebelum melakukan tes tertulis dan tes praktek calon pengemudi harus mendapatkan serangkaian pelatihan pembekalan berupa pelatihan $L V$ Awareness secara teori di dalam kelas dan praktik mengemudi untuk penanganankondisi daruratmenggunakan LVSimulator. Divisi OHS melakukan evaluasi dan perbaikan terhadap peraturan, prosedur dan rambu-rambu jalan serta melakukan razia / sweeping terhadap pengemudi untuk memastikan kepatuhan terhadap aturan. Divisi Maintenance membuat jadwal Prefentive Maintenance (PM) khusus pemeriksaan brake system setiap kendaraan menempuh jarak $2500 \mathrm{KM}$ diluar $P M$ general yang dilakukan setiap kendaraan menempuh jarak 5000 KM. Data kecelakaan periode Juli hingga November 2020 menunjukkan program ini efektif menurunkan kecelakaan hingga $44 \%$. Sebelum program ini berjalan kecelakaan kendaraan dari data tahun 2017 hingga bulan Mei 2020 rata-rata sebanyak 27 kecelakaan per bulan dan tidak sedikit menimbulkan kerusakan properti kategori berat, cedera pada karyawan bahkan korban jiwa. Pada periode lima bulan setelah berjalan program ini hanya terjadi 74 kecelakaan. Kerusakan properti sebanyak 77 kendaraan kategori ringan dan sedang dengan estimasi biaya perbaikan sebesar US\$57.750. Pada periode ini tidak terjadi cedera serta kematian pada karyawan akibat kecelakaan kendaraan. Program pencegahan kecelakaan tidak boleh hanya berhenti disini, perlu ditingkatkan lagi untuk mendapatkan hasil yang maksimal, sehingga kecelakaan kendaraan bisa lebih diturunkan lagi, bahkan dihilangkan. Melalui hasil identifikasi perbaikan program pencegahan kecelakaan menggunakan AHP maka PT FI dapat menerapkan perencanaan sumberdaya manusia yang merupakan peringkat tertinggi pada level tujuan AHP, dengan bobot 0,410 . Perencanaan sumberdaya manusia diimplementasikan dengan perencanaan jangka pendek dan jangka panjang. Perencanaan jangka pendek dilakukan dalam waktu satu hingga dua tahun kedepan. Perencanaan ini dilakukan melalui pelatihan peningkatan softskill dan hardskill kepada pengendara yang merupakan alternatif dengan bobot tertinggi pada analisis AHP $(0,289)$. Pelatihan peningkatan ini diberikan kepada pengemudi yang mempunyai kriteria perilaku tidak aman dan prasyarat perilaku tidak aman. Kriteria perilaku tidak aman merupakan faktor penyebab kecelakaan tertinggi pada CFIM 
$(82,7 \%)$ dan prasyarat perilaku tidak aman merupakan kriteria dengan bobot tertinggi pada level kriteria AHP $(0,404)$. Identifikasi kriteria pengemudi ini dilakukan oleh pengawas dan petugas K3/OHS. Pengawas atau atasan mengidentifikasi melalui observasi terhadap pengemudi, jika menemukan pengemudi yang berisiko segera melakukan tindakan korektif dan mendaftarkan pelatihan peningkatan berkendara. Petugas K3/OHS melakukan sweeping secara berkala kepada pengemudi untuk mengidentifikasi pengemudi yang tidak mematuhi peraturan dan tidak menjalankan prosedur dengan benar. Selanjutnya, pengemudi berisiko yang sudah diidentifikasi oleh pengawas atau petugas $\mathrm{K} 3$ / OHS didaftarkan pelatihan peningkatan softskill dan hardskill pada divisi Learning \& Organizatioanal Development (L\&OD). Pelatihan peningkatan softskill dilakukan melalui $L V$ Awareness Training Class. Peningkatan hardskill dilakukan dengan memberikan pelatihan keterampilan berkendara termasuk penanganan kondisi darurat menggunakan LV Simulator. Perencanaan jangka panjang dilakukan dengan memberikan pelatihan peningkatan softskill dan hardskill kepada seluruh pengendara ketika melakukan perpanjangan lisensi setiap tiga tahun sekali. Saat ini perpanjangan lisensi hanya melalui tes teori penyegaran yang dilakukan secara online, sehingga kurang efektif untuk meningkatkan pengetahuan dan keterampilan pengemudi. Penerapan pelatihan $L V$ Awareness dan pelatihan keterampilan menggunakan $L V$ simulator setiap perpanjangan lisensi akan efektif meningkatkan softskill dan hardskill pengemudi.

\section{Implikasi Manajerial}

Implikasi manajerial dari hasil penelitian ini dapat digunakan sebagai rekomendasi kepada manajemen PT FI untuk meningkatkan program pencegahan kecelakaan akibat pengoperasian kendaraan ringan. Perencanaan sumberdaya manusia yang mendapat bobot tertinggi $(0,410)$ pada level tujuan pada analisis AHP bisa menjadi kebijakan yang efektif untuk pencegahan kecelakaan kendaraan. Data menunjukkan sebagian besar kecelakaan kendaraan di PT FI dilakukan oleh pengemudi Non-PT FI (62\%). Perencanaan ini akan efektif mencegah kecelakaan kepada semua pengemudi baik pengemudi dari karyawan PT FI maupun Non-PT FI karena diterapkan kepada seluruh pengemudi.
Terlihat pada Tabel 1, perencanaan sumberdaya manusia yang merupakan skor tertinggi level tujuan pada AHP digunakan sebagai rekomendasi kepada PT FI untuk menurunkan kecelakaan akibat pengoperasian kendaraan. Pelaksanaan perencanaan dibagi dua, yaitu perencanaan jangka pendek dan jangka panjang. Kedua perencanaan sama-sama menerapkan pelatihan peningkatan pada pengemudi, yaitu pelatihan peningkatan softskill melalui $L V$ Awareness Training Class dan pelatihan peningkatan hardskill penanganan kondisi darurat menggunakan $L V$ Simulator yang merupakan skor tertinggi pada level alternatif pada AHP. Perencanaan jangka pendek pelatihan ini diberikan kepada pengemudi yang berisiko berdasarkan identifikasi dari atasan / pengawas pengemudi dan razia / sweeping yang dilakukan oleh petugas $O H S$. Perencanaan jangka panjang pelatihan peningkatan ini akan diberikan kepada seluruh pengemudi ketika melakukan proses perpanjangan lisensi setiap tiga tahun sekali.

\section{KESIMPULAN DAN SARAN}

\section{Kesimpulan}

Faktor yang paling berpengaruh terhadap kecelakaan akibat pengoperasian kendaraan ringan di PT FI adalah akibat perilaku tidak aman pengemudi. Perilaku tidak aman karena pengemudi melakukan kesalahan ataupun pelanggaran. Perencanaan yang paling tepat untuk menurunkan jumlah kecelakaan akibat pengoperasian kendaraan ringan di PT FI adalah perencanaan sumberdaya manusia dengan memberikan pelatihan peningkatan softskill dan hardskill pada pengemudi. Pelatihan softskill untuk meningkatkan pemahaman peraturan dan kepedulian terhadap keselamatan. Pelatihan hardskill untuk meningkatkan keterampilan pengemudi. Berdasarkan faktor yang memengaruhi dan hasil AHP, perencanaan yang paling tepat sebagai rekomendasi yang diberikan kepada manjemen PT FI adalah perencanaan sumberdaya manusia. Perencanaan jangka pendek dilakukan melalui peningkatan pelatihan softskill dan hardskill pada pengemudi yang bersiko dari hasil identifikasi pengawas dan sweeping petugas K3. Perencanaan jangka panjang dilakukan dengan memberikan pelatihan peningkatan softskill dan hardskill pada seluruh pengemudi setiap perpanjangan lisensi tiga tahunan. 
Tabel 1. Implikasi manajerial

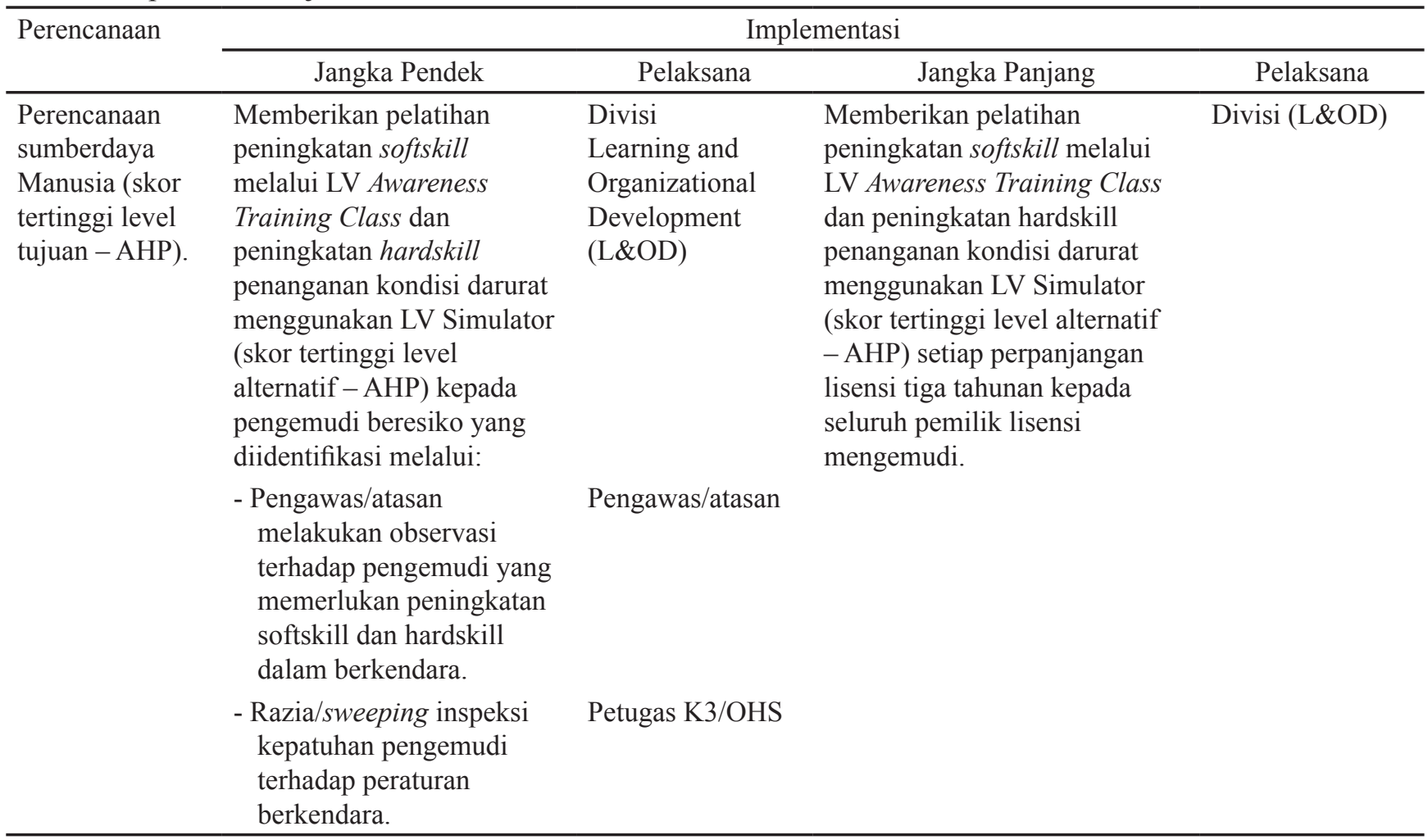

\section{Saran}

PT FI saat ini sudah memiliki IMS, merupakan sistem yang dirancang dengan baik sebagai monitoring insiden. Namun pada pelaksanaanya perlu ditingkatkan lagi agar tim investigasi kecelakaan dan petugas $\mathrm{K} 3$ dilapangan baik dari PT FI maupun Non-PT FI lebih konsisten untuk melakukan input informasi-informasi yang seharusnya dilaporkan. Informasi-informasi hasil investigasi pada ISIIR saat ini hanya sebagian saja yang diinput pada IMS sehingga informasi causal faktor hasil investigasi kecelakaan tidak bisa didapatkan secara keseluruhan sebagai dasar untuk keakuratan perencanaan pencegahan kecelakaan.

\section{DAFTAR PUSTAKA}

Ahmadi I, Ahmadi S, Hosseini T, Hosseinian S, Chegini D, Kashfi SS. 2018. Evaluating and prioritizing factors affecting road traffic accident relief in Iran. Quarterly Scientific Journal of Rescue and Relief 10(3):35-41.

Bogner A, Menz W. 2009. The Theory-Generating Expert Interview: Epistemological Interest, Forms of Knowledge, Interaction. Interviewing experts. London: Palgrave Macmillan.

Borovik, VS, Borovik VV, Skorobogatchenko D. 2018. Model of the strategy for reducing the road accident rate in the city. Transportation Research Procedia 36(1):68-76. https://doi.org/ 10.1016/j. trpro.2018.12.045

Brusque C, Alauzet A. 2008. Analysis of the individual factors affecting mobile phone use while driving in France: Socio-demographic characteristics, car and phone use in professional and private contexts. Accident Analysis \& Prevention 40(1):35-44. https://doi. org/10.1016/j.aap.2007.04.004

Herawati. 2014. Karakteristik dan penyebab kecelakaan lalu lintas di Indonesia tahun 2012. Warta Penelitian Perhubungan 26(3):133-142.

Holillulloh W, Adha MM. 2013. Pengaruh sangsi tilang bagi pelanggar terhadap kedisiplinan dalam berlalu lintas. Jurnal Kultur Demokrasi 3(7):115.

Hughes BP,Anund A, Falkmer T. 2016.Acomprehensive conceptual framework for road safety strategies. Accident Analysis \& Prevention 90(1):13-28. https://doi.org/10.1016/j/aap.2016.01.017

Jeong BY, Lee S, Park MH. 2016. Driving conditions and occupational accident management in large truck collisions. Journal of the Ergonomics Society of Korea 35(3):135-142. https://doi. org/10.5143/JESK.2016.35.3.135

Kordelia DC, Yossyafra, Kurniati T. 2014. Model kecelakaan lalu lintas berdasarkan korelasi populasi, tingkat pemahaman pengguna dan 
tingkat pertumbuhan kendaraan di kota besar, sedang dan kecil Sumatera Barat. Jurnal Rekayasa Sipil 10(1):22-31.

Malin F, Norros I, Innamaa S. 2019. Accident risk of road and weather conditions on different road types. Accident Analysis and Prevention 122(1):181-188. https://doi.org/10.1016/j. aap.2018.10.014

Meuser M, Nagel U. 2009. The Expert Interview and Changes in Knowledge Production. In: Interviewing Experts. London: Palgrave Macmillan.

Qin C, Zhang Y. 2016. Evaluation of the safety of mine road based on fuzzy analytic hierarchy process. Journal of transportation technologies 7(1):70-82.

Ren K, Wang Q, Wang C, Qin Z, Lin X. 2019. The security of autonomous driving: Threats, defenses, and future directions. Proceedings of the IEEE 108(2):357-372. https://doi. org/10.1109/JPROC.2019.2948775.

Riani ME, Maarif SM, Affandi J. 2017. Pengaruh program pelatihan dan motivasi kerja terhadap kinerja karyawan PT Td Automotive Compressor Indonesia. Jurnal Aplikasi Bisnis dan Manajemen 3(2): 290-298. https://doi.org/10.17358/ jabm.3.2.290

Saaty RW. 1987. The analythical hierarchy process - what it is and how it is used. Mathematical modelling 9(5):161-176.

Saaty TL. 1986. Axiomatic foundation of the analytic hierarchy process. Management science 32(7):841-855.
Saaty TL, Kearns KP. 1985. Analytical Planning the Organization of System. Pittsburgh: Pergamon press.

Sandhyavitri A, Zamri, Wiyono S, Subiantoro. 2017. Three strategies reducing accident rates at black spots and black sites road in Riau province, Indonesia. Transportation Research Procedia 25C(1):2158-2171. https://doi.org/10.1016/J/ TRPRO.2017.05.415

Siahaan R. 2013. Pengaruh reward dan punishment terhadap disiplin kerja karyawan pada PT. Perkebunan Nusantara III Rambutan. Jurnal Ilmiah Business Progress 1(1):17-26.

Trimpop R. Kirkcaldy B. 1997. Personality predictors of driving accidents. Personality and Individual Differences 23(1):147-152.

Xiong Y, Mannering FL. 2013. The heterogeneous effects of guardian supervision on adolescent driver-injury severities: A finite-mixture randomparameters approach. Transportation research part B: methodological 49(2013):39-54. https:// doi.org/10.1016/j.trb.2013.01.002

Zhang M, Kecojevic V. 2015. Intervention strategies to eliminate truck-related fatalities in surface coal mining in west virginia. International Journal of Injury Control and Safety Promotion 23(2):1-14. https://doi.org/10.1080/17457300.215.1032982

Zhang Y, Liu T, Bai Q, Shao W, Wang Q. 2018. New systems-based method to conduct analysis of road traffic accidents. Transportation Research Part F: Traffic Psychology and Behaviour 54(1):96109. https://doi.org/10.1016/j/trf2018/01/019 